Ankara Sağllk Hizmetleri Dergisi,

Cilt 11, Sayı 1, 2012

\title{
Halluks Valgus Deformitesinin Yaşam Kalitesi Üzerine Etkisi
}

\author{
Bahar ANAFOROĞLU \\ Başkent Üniversitesi Sağlık Bilimleri Fakültesi Fizyoterapi ve Rehabilitasyon Bölümü, Ankara, \\ Türkiye,anaforoglu@baskent.edu.tr
}

\begin{abstract}
Özet
Bu çalışmanın amacı halluks valgus (HV) şiddetinin genel ve ayağa özel sağlıkla ilgili yaşam kalitesi üzerine etkisini incelemekti. Çalışmaya yaşları 16-80 yıl arasında değişen, halluks valguslu toplam 263 (139 kadın, 124 erkek) hasta dahil edilmiştir. Genel sağlıkla ilgili yaşam kalitesi Kısa Form-36 (SF-36), hastalığa özel yaşam kalitesi Amerikan Ortopedik Ayak ve Ayak Bileği Birliği'nin başparmak için klinik ölçümleme sistemi kullanılarak, deformitenin açısal şiddeti gonyometrik ölçümle değerlendirildi. HV'un açısal şiddetindeki artışla SF-36 alt skalaları olan Fiziksel Fonksiyon, Vitalite ve Mental Sağlığı her iki ayak için $(\mathrm{p}=0,00)$, sağ ayak için Fiziksel Rolü $(p=0,00)$, Emosyonel Rolü $(p=0,01)$, Ağrı $(p=0,00)$, Genel Sağlık $(p=0,003)$ ve Amerikan Ortopedik Ayak-Ayak Bileği Derneği (AOFAS) başparmak alt skalası $(\mathrm{p}=0,001)$ ve sol ayak için Fiziksel Rolü ( $p=0,001)$, Emosyonel Rolü ( $p=0,03)$, Ağr1 ( $p=0,009)$, Genel Sağlık ( $p=0,03)$ ve AOFAS başparmak alt skalası $(\mathrm{p}=0,00)$ skorlarının azaldı $\breve{g}$ s saptandı. HV şiddeti arttıkça genel ve ayağa özel sağlıkla ilgili yaşam kalitesi azalmıştır. SF-36 ve AOFAS sonuç anketleri klinik halluks valgus çalışmalarında temel ölçüm yöntemleri olarak kullanılabilir. SF-36 ve AOFAS skorlarının yükseltilmesinde fizyoterapi ve rehabilitasyon önerilmektedir.
\end{abstract}

Anahtar Kelimeler: Halluks valgus, SF-36, AOFAS, yaşam kalitesi

\begin{abstract}
The purpose of this study was to assess the impact of hallux valgus severity on general and footspesific health related quality of life (HRQOL). Two hundred and sixty three subjects (139 women, 124 men) aged between 16-80 with hallux valgus were enrolled in this study. Measures used were the quality of life according to SF-36, a disease spesific score (the American Orthopeadic Foot and Ankle Society's (AOFAS) clinical rating system for the hallux), angular severity of the deformity by a goniometer. The severity of hallux valgus angle (HVA) significantly affected SF-36 subsclaes the Physical Function, Vitality and Mental Health $(\mathrm{p}=0,00)$ for both feet, the Role Physical $(\mathrm{p}=0,00)$ for right and $(\mathrm{p}=0,001)$ for left foot, Role Emotional $(\mathrm{p}=0,001)$ for right and $(p=0,03)$ for left foot, the Bodily Pain $(p=0,00)$ for right and $(p=0,009)$ for left foot, the General Health $(\mathrm{p}=0,003)$ for right and $(\mathrm{p}=0,03)$ for left foot and the AOFAS score for the hallux $(p=0,001)$ for right and $(p=0,00)$ for left foot. There is a reduction for both general and footspesific HRQOL with increasing severity of hallux valgus deformity. These data may serve as a baseline for clinical hallux valgus studies with use of the SF-36 or the AOFAS outcome questionnaire. Physiotherapy and rehabilitation is warrented to normalize the SF-36 and AOFAS scores.
\end{abstract}

Keywords: Hallux valgus, SF-36, AOFAS, quality of life 


\section{Giriş}

Halluks valgus (HV) deformitesi, başparmağın lateral, birinci metatarsal kemiğin medial deviasyonu nedeniyle birinci metatarsofalangeal eklemin sublukse olduğu, çok sık görülen bir deformitedir (1). Bu duruma sıklıkla 1. metatars başının medial kısmında "bunyon" olarak tanımlanan kemik çıkıntısı ve yumuşak doku ağrısı eşlik eder. Deformite ilerlerken başparmağın laterale doğru yer değiştirmesi, diğer parmaklarda pençe ve çekiç parmak deformiteleri ve nasır oluşumuyla beraber fonksiyon ve düzgünlüğün kaybına neden olur (2). Ayakkabının bunyon olan bölgeye yaptı̆̆ı bası, bursada enflamasyon ve ağrıya yol açmaktadır (3).

HV deformitesinin nedeni tam olarak anlaşılamamıştır. HV deformitesine sahip kişilerin yaklaşık \%90'ının pozitif aile öyküsünün olması nedeniyle deformitenin otozomal dominant olduğuna dair bazı kanitlar mevcuttur (4). Diğer nedenler arasında yüksek topuklu ve dar parmak kutusu olan uygun olmayan ayakkabı giyme alışkanlığı ve 1 . metatarsal kemiğin aşırı derecede uzun olması, metatars başının yuvarlak olması, intermetatarsal açının geniş olması ve ayağın pronasyon postüründe olması gibi nedenler yer almaktadır (5).

HV deformitesinin prevalansı farklı popülasyonlarda değişmekle birlikte, \%21-65 arasında olduğu bildirilmiştir (6-9). Kadınlarda HV görülme sıklığının 9:1 oranında erkeklere göre daha fazla olduğu, yaşla beraber bu oranın arttığı bildirilmiştir $(8,9)$. HV deformitesi gözlemsel olarak "var" ya da "yok" şeklinde değerlendirilirken, şiddetinin sınıflandırılmasında geçerli envanterler geliştirilmiş̧ir $(10,11)$. Şiddetin değerlendirilmesinde en sık kullanılan yöntem açısal derecenin ölçülmesidir (12, 13). Deformitenin denge, yürüyüş ve ağırlık aktarımını olumsuz yönde etkilediği ve yaşlılarda düşme riskini artırdığı rapor edilmiştir $(14,15)$. Bazı çalı̧̧malarda HV deformitesinin sağlıkla ilgili yaşam kalitesi üzerine olumsuz etkileri olduğu gösterilmiştir (16-18). Bu çalışmanın amacı HV deformitesinin açısal şiddetinin genel ve ayağa özel sağlıkla ilgili yaşam kalitesi üzerine etkisini incelemekti.

\section{Gereç ve Yöntemler}

Çalışmamızda Başkent Üniversitesi Hastanesi Fizik Tedavi ve Rehabilitasyon Poliklinik'ine başvuran nörolojik veya alt ekstremiteye ait herhangi bir ortopedik problemi olmayan 520 (278 kadın ve 242 erkek) bireyin ayakları incelenmiştir. Bu bireyler arasından Manchester Skalası'na (Şekil 1) göre HV şiddeti B veya C değerinde olan bilateral HV deformitesine sahip 263 olgu çalışmaya dahil edilmiştir. Manchester Skalası HV deformitesinin olmadığı bir ve hafif, orta ve şiddetli deformitenin temsil edildiği üç HV'lu ayak resminden oluşan, geçerliliği ve güvenilirliği gösterilmiş bir ölçümleme yöntemidir. Bu skalaya göre standart ayakta dik duruş pozisyonunda gözlemsel olarak olguların ayakları değerlendirilmiştir (19). Bireylerin yaş, cinsiyet gibi sosyodemografik ve vücut kütle indeksi gibi fiziksel özellikleri kaydedilmiştir. 
A

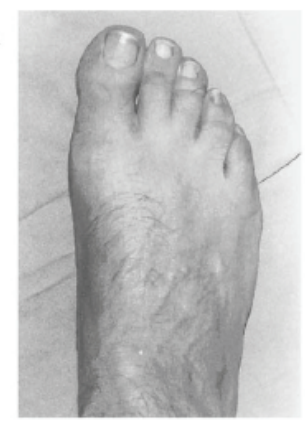

C

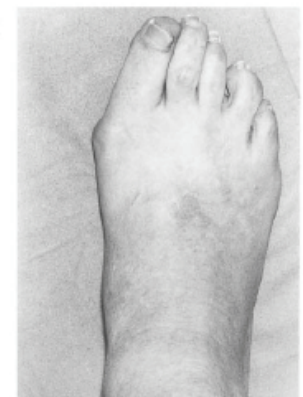

B

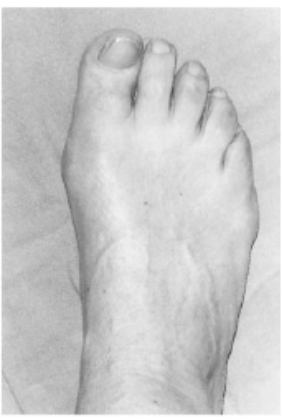

D

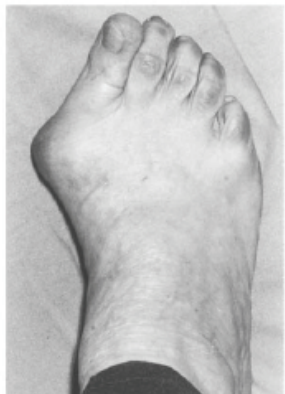

Şekil 1: Manchester Skalası: A: deformite yok, B: Hafif şiddette HV,

C: orta şiddette $H V$, D: çok şiddetli $H V$

(BMC Musculoskeletal Disorders 2010;11: 215)

Birinci metatarsofalangeal eklem/HV açısı dijital gonyometre (Şekil 2) ile ayakta dik duruş pozisyonunda ölçülmüş̧ür. Gonyometrenin pivot noktası 1. metatarsofalangeal ekleme yerleştirilmiş, bir kolu 1. metatarsal kemiğe, diğer kolu proksimal falanksa paralel olacak şekilde yerleştirilerek ölçüm gerçekleştirilmiştir (20).

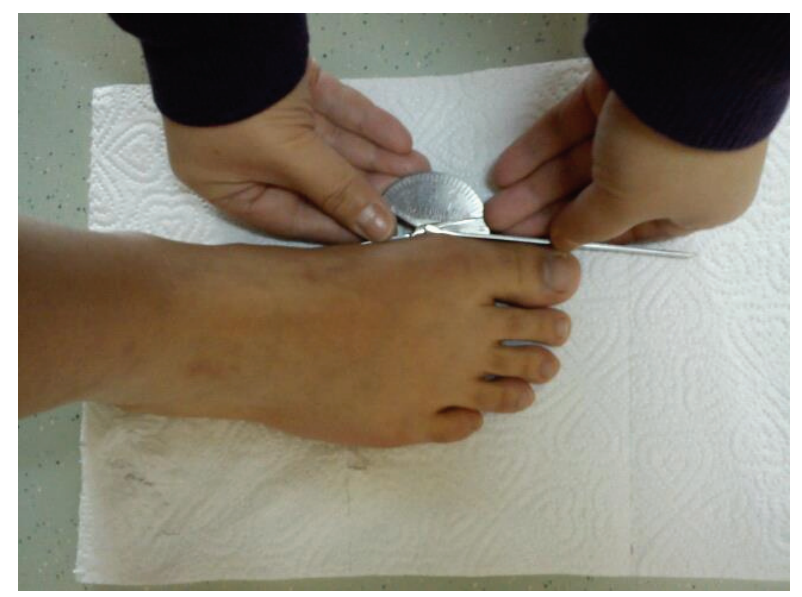

Şekil 2. Halluks valgus açısal şiddetinin gonyometre ile ölçümü

Genel sağlıkla ilgili yaşam kalitesi Kısa Form-36 (SF-36), hastalığa özel yaşam kalitesi Amerikan Ortopedik Ayak ve Ayak Bileği Birliği'nin başparmak (AOFAS-hallux MTP-IP alt skalası) için klinik ölçümleme sistemleri kullanılarak değerlendirilmiştir. SF-36 fiziksel fonksiyon, fiziksel sağlık problemlerinden kaynaklanan rol kısıtlamaları, ağrı, sosyal fonksiyon, mental sağlık (psikolojik sıkıntı 
ve psikolojik iyilik), emosyonel problemlerden kaynaklanan rol kısitlamaları, vitalite (enerji ve yorgunluk) ve genel sağlık algılamasını ölçen sorulardan oluşmuş yaşam kalitesini değerlendiren bir ankettir. Anketin toplam skoru 100'dür. Yüksek skor iyi sağlı̆̆ı, düşük skor ise kötü sağllğ ifade eder. AOFAS sonuç ölçümü ise ayağın 3 farklı bölümünün (arka ayak, orta ayak ve halluks metatarsofalangeal- interfalangeal) ağrı, fonksiyon ve dizilimi değerlendiren 100 puanlık bir skorlama sistemidir (21-23).

Çalışmada elde edilen bulgular değerlendirilirken, istatistiksel analizler için SPSS (Statistical Package for Social Sciences for Windows) 15.0 programı kullanıldı. Çalışmamız sonucunda elde edilen veriler, aritmetik ortalama ve standart sapma olarak verildi. Tüm veriler arasındaki ilişkiye bakmak amacıyla "Pearson Korelasyon Analizi" kullanıldı. İstatistiksel anlamlılık düzeyi p<0,05 olarak kabul edilmiştir.

\section{Bulgular}

Çalışmamıza katılan 263 bireyden 139'u bayan 124'ü erkek olup, yaşları 16-80 yıl arasında (ortalama 27, $2 \pm 16$ ) değişmekteydi. Bireylerin ortalama Vücut Kütle İndeksi 23, $88 \pm 4$ 'dir (Bkz. Tablo 1). Bireylerin hem sağ hem de sol ayakları için HV açısal şiddeti ile SF-36 alt parametreleri arasındaki ilişki incelendiğinde, 'Sosyal Fonksiyon alt parametresi' dışındaki tüm parametrelerin ve AOFAS-hallux MTP-IP alt skalasının açısal şiddet ile negatif bir ilişkisi olduğu tespit edilmiştir (Bkz. Tablo 2).

Tablo1. Çalışmaya katılan olguların sosyodemografik özellikleri

\begin{tabular}{|l|l|}
\hline \multicolumn{2}{|c|}{ Bireyler } \\
\hline Bayan $(\mathrm{N})$ & 139 \\
\hline Erkek $(\mathrm{N})$ & 124 \\
\hline Yaş $(\mathrm{X} \pm \mathrm{SD})$ & $27,2 \pm 16$ \\
\hline Vücut Kütle İndeksi $(\mathrm{X} \pm \mathrm{SD})$ & $23,88 \pm 4$ \\
\hline
\end{tabular}

Tablo 2. Să̆ ve sol ayak HV açısal şiddeti ile SF-36 ve AOFAS Halluks Alt Skalası Arasındaki Korelasyon Illişkisi, $r$ : Pearson Korelasyonu, $p<0,05$

\begin{tabular}{|c|c|c|c|c|c|}
\hline \multirow{10}{*}{$\begin{array}{l}\text { SF-36 } \\
\text { Alt Skalaları }\end{array}$} & & \multicolumn{2}{|c|}{ Sağ Ayak HV Açısal Şiddeti } & \multicolumn{2}{|c|}{$\begin{array}{c}\text { Sol Ayak HV Açısal } \\
\text { Şiddeti }\end{array}$} \\
\hline & & $\mathrm{r}$ & $\mathrm{p}$ & $\mathrm{r}$ & $\mathrm{p}$ \\
\hline & Fiziksel Fonksiyon & $-0,39$ & 0,00 & $-0,31$ & 0,00 \\
\hline & Fiziksel Rol & $-0,25$ & 0,00 & $-0,20$ & 0,001 \\
\hline & Ăgrn & $-0,22$ & 0,00 & $-0,16$ & 0,009 \\
\hline & Genel Sağlık & $-0,18$ & 0,003 & $-0,13$ & 0,03 \\
\hline & Vitalite & $-0,39$ & 0,00 & $-0,33$ & 0,00 \\
\hline & Emosyonel Rol & $-0,14$ & 0,01 & $-0,13$ & 0,003 \\
\hline & Mental Sağlık & $-0,26$ & 0,00 & $-0,22$ & 0,00 \\
\hline & Sosyal Fonksiyon & $-0,042$ & 0,50 & $-0,003$ & 0,96 \\
\hline AOFAS Halu & s Alt Skalası & $-0,20$ & 0,001 & $-0,22$ & 0,00 \\
\hline
\end{tabular}

\section{Tartışma}

Çalışmamızda SF-36'nın 'Sosyal Fonksiyon' alt parametresi dışında tüm alt parametrelerinin HV'un açısal şiddeti ile negatif bir ilişkisi olduğu, açısal şiddet arttıkça yaşam kalitesinin olumsuz etkilendiği tespit edilmiştir. HV yetişkin popülasyonda oldukça sık görülen başparmağın lateral ve 1 . 
metatarsal kemiğin medial deviasyonu ile seyreden bir deformitedir (24). Birinci metatarsofalangeal eklemin laterale deviasyonuyla beraber kas, bağ ve tendonların çekiş açısı eklemin hareket eksenine göre yer değiştirerek, ekleme etkiyen kuvvet vektörünün çekiş açısı bozar, böylece lateral deviasyon ve dolayısıyla deformitenin şiddetinin artmasına neden olur (25).

HV üzerine yapılan birçok çalışma, komplikasyonlar ve deformitenin azaltılması üzerine yoğunlaşmıştır. Çok az sayıda çalışmanın HV ile genel sağlık durumu ve yaşam kalitesi arasındaki ilişkiyi incelediği tespit edilmiştir (26). Dünya Sağlık Örgütü, yaşam kalitesini "hedefleri, beklentileri, standartları, ilgileri ile bağlantılı olarak, kişilerin yaşadıkları kültür ve değer yargılarının bütünü içinde durumlarını algılama biçimi" olarak tanımlar. Bir diğer ifadeyle; yaşam kalitesi kişinin içinde yaşadığı sosyokültürel ortamda kendi sağlığını öznel olarak algılayışını tanımlamaktadır (27). Yaşam kalitesi fonksiyonel durum, ağrı gibi fiziksel semptomlar ve depresyon gibi psikolojik faktörlerden etkilenebilir. Sağlıkla ilgili yaşam kalitesi kavramı farklı hastalıkların ya da problemlerin tedavisinin etkinliğinde giderek daha yoğun biçimde kullanılmaktadır (28).

Bir çalışmada HV deformitesinin cerrahi girişimle düzeltilmesinden sonra bireylerin bozulmuş olan yaşam kalitelerinin belirgin şekilde düzeldiği rapor edilmiştir (29). Bu çalışmada bireylerin sosyal fonksiyonlarında bir değişiklik olmadı̆̆ı, bunun da genel sağlığın fiziksel sağlı̆̆a göre daha subjektif olarak algılanmasından kaynaklandığı önerilmiştir. Ayrıca daha özelleşmiş değerlendirme envanterlerinin patolojinin yaşam kalitesi üzerine etkisini daha belirgin olarak ortaya koyabileceği sonucuna varılmışır. Çalışmamız sonuçlarına benzer olarak Lazarides ve arkadaşlarının yaptığı çalışmada SF-36 Genel Sağlık, Fiziksel ve Emesyonel Rol Güçlüŭü, Mental Sağlık alt parametrelerinin HV'un açısal şiddetinden belirgin şekilde etkilendiği tespit edilmiştir (16). Saro ve arkadaşlarının 94 HV'lu kadın üzerinde yaptıkları çalışmada genel popülasyonla karşılaştırıldığında bireylerin yaşam kalitelerinin daha düşük olduğu, açısal şiddetle SF-36 ve AOFAS-MTF-IP skorları arasında herhangi bir ilişki olmadığı tespit edilmiştir. Bu çalışmada cerrahi girişimden SF-36 skorlarında belirgin düzelme olduğu saptanmıştır (18). Bu çalışmadaki sonuçlara benzer olarak Thordarson genel poülasyonla karşılaştırıldığında HV'lu hastaların SF-36- ağrı alt skalası değerlerinin daha düşük olduğunu rapor etmiştir (17). Benzer olarak 6 yıllık takip ile 2831 hastanın dahil edildiği bir çalışmada HV'un açısal şiddeti ile genel ve ayağa özel yaşam kalitesi skorları arasında negatif bir ilişki olduğu saptanmıştır (30).

Çalışmamızın sonuçları daha önce yapılan çalışmalarla paralellik göstermiştir. HV'un açısal şiddetinin yaşam kalitesi üzerine olumsuz etkileri olduğu saptanmıştır. Daha önce yapılan bir çalışmada (31) HV şiddetinin ölçülmesinde radyografik ve gonyometrik ölçümler arasında iyi bir korelasyon olduğu tespit edilmesine rağmen çalışmamızın limitasyonu olarak cilt üstünden yapılan gonyometrik ölçümde bunyon nedeniyle kemiksel deviasyonun şiddetinin normalden daha büyük çıkabileceği göz önünde bulundurulmalıdır.

\section{Sonuç}

Çalı̧̧mamızda 'Sosyal Fonksiyon' hariç SF-36 alt parametreleri ve AOFAS- halluks metatarsofalangeal- interfalangeal alt parametresi ile HV'un açısal şiddeti arasında negatif yönde belirgin bir korelasyon olduğu tespit edilmiştir. HV açısı arttıkça, genel ve ayağa özel yaşam kalitesinin bozulduğu, bu hastaların değerlendirilmesi ve tedavi alternatiflerinin sonuçlarının değerlendirilmesinde yaşam kalitesi kavramının da ele alınması gerektiği sonucuna varılmıştır.

\section{Kaynaklar}

[1] Mann R, Coughlin M. Hallux valgus: etiology, anatomy, treatment and surgical considerations. Clin Orthop Relat Res 1981; 157:31-41.

[2] Spink MJ, Menz HB, Lord SR. Distribution and correlates of plantar hyperkeratotic lesions in older people. J Foot Ankle Res 2008;2:8.

[3] Thomas S, Barrington R. Hallux valgus. Curr Orthop 2003;17: 299-307. 
[4] Pique-Vidal C, Sole MT, Antich J. Hallux valgus inheritance: pedigree research in 350 patients with bunion deformity. J Foot Ankle Surg 2007;46:149-154

[5] Kilmartin TE, Wallace WA. The aetiology of hallux valgus: a critical review of the literature. Foot 1993;3:157-67

[6] Crawford VL, Ashford RL, McPeake B ve ark. Conservative podiatric medicine and disability in elderly people. J Am Podiatr Med Assoc 1995; 85: 255-259.

[7] Benvenuti F, Ferrucci L, Guralnik JM ve ark. Foot pain and disability in older persons: an epidemiologic survey. J Am Geriatr Soc 1995; 43: 479-484.

[8] Dunn JE, Link CL, Felson DT ve ark. Prevalence of foot and ankle conditions in a multiethnic community sample of older adults. Am J Epidemiol 2004; 159: 491-498.

[9] Cho NH, Kim S, Kwon DJ ve ark. The prevalence of hallux valgus and its association with foot pain and function in a rural Korean community. J Bone Joint Surg Br 2009; 91: 494-498.

[10] Garrow AP, Papageorgiou A, Silman AJ ve ark. The grading of hallux valgus: the Manchester Scale. J Am Podiatr Med Assoc 2001; 91: 74-78.

[11] Roddy E, Zhang W, Doherty M. Validation of a self-report instrument for assessment of hallux valgus. Osteoarthritis Cartilage 2007; 15: 1008-1012.

[12] Coughlin MJ, Freund E. The reliability of angular measurements in Hallux Valgus deformities. Foot Ankle Int $2001 ; 22(5)$.

[13] Coughlin MJ, Saltzman CL, Nunley JA. Angular measurements in the evaluation of Hallux Valgus deformities; a report of the ad hoc committee of the American Orthopaedic Foot \& Ankle Society on angular measurements. Foot Ankle Int 2002; 23 (1): 68-74.

[14] Menz HB, Morris ME, Lord SR. Foot and ankle characteristics associated with impaired balance and functional ability in older people. J Gerontol A Biol Sci Med Sci 2005; 60: 1546-1552.

[15] Menz HB, Lord SR. Gait instability in older people with hallux valgus. Foot Ankle Int 2005; 26: $483-489$.

[16] Lazarides SP, Hildreth A, Prassanna V ve ark. Association amongst angular deformities in hallux valgus and impact of the deformity in health-related quality of life. Foot Ankle Surg 2005; 11: 193-196.

[17] Thordarson DB, Ebramzadeh E, Rudicel SA ve ark. Age adjusted baseline data for women with hallux valgus undergoing corrective surgery. J Bone Joint Surg Am 2005; 87: 66- 75.

[18] Saro C, Jensen I, Lindgren U ve ark. Quality-of-life outcome after hallux valgus surgery. Qual Life Res 2007; 16: 731-8.

[19] Menz HB, Fotoohabadi MR, Wee E ve ark. Validity of self-assessment of hallux valgus using the Manchester scale. BMC Musculoskeletal Disorders 2010; 11: 215

[20] Kilmartin TE, O'Kane C. Combined rotation scarf and A kin osteotomies for hallux valgus: a patient focussed 9 year foolow up of 50 patients. Journal of Foot and Ankle Research 2010; 3: 2

[21] Koçyiğit H, Aydemir Ö. ve Fişek G. Kısa Form-36'nın (KF-36) Türkçe için güvenilirliği ve geçerliliği. Romatizmal hastalığı olan bir grup hasta ile çalışma. İlaç ve Tedavi Dergisi 1999; 12: 102-106.

[22] Bek N, Şimşek E, Erel S ve ark. Correlation Between the AOFAS Ankle-Hindfoot Scale, Foot Function Index , and Nottingham Health Profile in Foot Assessment. EULAR, 13-16 June 2007, Barcelona, Spain. Annals of the Rheumatic Diseases 2007; 66 (2): 650.

[23] SooHoo NF, Shuler M, Fleming LL. American Orthopaedic Foot and Ankle Society. Evaluation of the validity of the AOFAS Clinical Rating Systems by correlation to the SF-36. Foot Ankle Int. 2003; 24(1): 50-55.

[24] Kilmartin TE, Barrington RL, Wallace WA. A controlled prospective trial of a foot orthosis for juvenile Hallux Valgus. J Bone Joint Surg Br 1994; 76: 210-4.

[25] Snijders CJ, Snijder JGN, Philippens MMGM. Biomechanics of Hallux Valgus and spread foot. Foot Ankle 1986; 7: 26-39. 
[26] Parker J, Nester CJ, Long AF ve ark. The problem with measuring patient perceptions of outcome with existing outcome measures in foot and ankle surgery. Foot Qual Life Res 2007; 16: 731-738.

[27] Trudel L, Fabia J, Bouchard JP. Quality of life of 50 carotid endarterectomy survivors: a long-term followup study. Archives of Physical Medicine and Rehabilitation 1984; 65(6): 310-312.

[28] Poljak-Guberina R. The Amputees and Quality of Life. Collegium Antropologicum 2005; 29 (2): $603-609$

[29] Cohen P, Zanardo D, Galois L ve ark. Qualite de vie apre`s chirourgie de l' Hallux Valgus. Etude prospective a propos de 30 cas. Med Chir Pied 2000; 3: 91-97.

[30] Menz HB, Roddy E, Thomas E ve ark. Impact of Hallux Valgus Severity on General and Foot-Specific Health-Related Quality of Life. Arthritis Care \& Research Vol 2011; 63(3): 396-404

[31] Kilmartin TE: Phd Thesis: The orthotic treatment of juvenile hallux valgus. Nottingham University, Department of Orthopaedic and Accident Surgery 1994, 108-110. 